\title{
The Reconciliation Between Individuality and Universality in Spirit: On the Task of Hegel's Aesthetics
}

\author{
Liu Chunge, Qin Mingli \\ Dalian University of Technology
}

\begin{abstract}
Under the background of binary opposition of modern philosophy and aesthetics, Hegel takes "spirit" as the starting point and aims to achieve the reconciliation between binaries through the dialectical development of spirit. At the same time, this process also makes spirit reach its own self-consciousness and self-realization. Among many oppositions and contradictions, one of the key issues that Hegel attempts to deal with is the relationship between individuality and universality in spirit. In Hegel's view, spirit is universal self-consciousness, a unity of individuality and universality. Consistent with his philosophy, the task of his aesthetics is also to reconcile universality and individuality in spirit. In Aesthetics, this settlement is mainly reflected in three aspects, namely the unity of content and form, the unity of the general world situation, and the character and finally the unity of subjective artistic creation and objective performance. In this way, Hegel's Aesthetics bridges the distance between individuality and universality, achieving the goal of self-consciousness and self-realization in spirit, thus giving his response to the problem of binary opposition caused by modern philosophy and aesthetics.
\end{abstract}

Keywords: Hegel, Aesthetics, spirit, individuality, universality, reconciliation

Hegel develops his thought under the background of modern philosophy and aesthetics. A striking feature and main problem of modern philosophy and aesthetics is binary opposition. Therefore, how to achieve their unification is an important task with which modern philosophers are faced. Bernard Bosanquet points out in $A$ History of Aesthetics that the general form of the modern philosophical question is "how we can reconcile the sensory world with the ideal world?" And the aesthetic form of that question is "how sense of pleasure can share the nature of reason?” (Bosanquet 2010, 170) It can be seen that in both the general form and the aesthetic form, the problem here involves the relationship between the sensory world and the rational world, between sensibility and rationality. Other manifestations of this problem include the relationship between necessity and freedom, universality and particularity, phenomenon and noumenon. Modern philosophers and aestheticians devote themselves to explaining the relationship between binaries at different levels and make efforts to reconcile the contradiction between them. There is no denying that there does exist binaries in the ancient time and the medieval age. For example, Plato's concept of the world is divided into the intellectual world and the world of the senses. Also, in the medieval religion, there is the distinction between "here" and

Liu Chunge, Ph.D. student, School of Humanities, Dalian University of Technology, China; main research field: Hegel's Philosophy and Aesthetics.

Qin Mingli, professor, School of Foreign Languages, Dalian University of Technology, China; main research field: Philosophy of Literature, Hermeneutics, and Western Philosophy.

This paper is supported by the Basic Scientific Research Fund of Dalian University of Technology (Key Project, DUT17RW209). 
"there," the opposition between man and God. However, the contradiction between the "dual" is highlighted with the rise of modern Christian consciousness. Meanwhile, with the appearance of "binary opposition," modern philosophers are committed to mediating the conflicts between these binaries. Hegel's philosophy and aesthetics take the binary problem as a main task and are especially devoted to reconciling the contradiction between universality and individuality in spirit.

\section{The Problem of Individuality and Universality}

In modern times, the conflict between universality and individuality is especially obvious. Besides, with the enhancement of individual consciousness, the contradiction between universality and individuality is further intensified. In the ethical world of ancient Greece, the universal substance which is represented by the polis and the individual was in a natural unity. In the middle ages, universality dominated, and individuals crawled under the absolute substance. But in the modern society, especially with the reform of religion, religious consciousness has turned from the worship of God as an unattainable absolute substance to the "incarnation" of Christ, and then to the faith of the holy spirit in the individual themselves. In this process, individuality is recognized and strengthened. Individuality has gradually gained advantages and become a power to compete with universality, but the conflict between them has also been highlighted. The rationalists, represented by Descartes, stand on the standpoint of innate rationality and tend to be universal. The empiricists start from perceptual experience and emphasize individuality. However, the long-term argument in modern philosophy between rationalists and empiricists suggests that universality and individuality, reason and sensibility, necessity and freedom are not completely separate and opposite to each other. The two schools of thought have both rational and emotional characteristics, and there are both conflict and integration between universality and individuality. It is in the context of the struggle between universality and individuality that Hegel's philosophy and aesthetics are committed to the reconciliation between universality and individuality through the dialectical development of spirit.

"Spirit" is a key concept of Hegel's philosophy. To some extent, all of Hegel's philosophy is based on the concept of "spirit," so "spirit” is the "key" to open Hegel's philosophical edifice. The three parts of Hegel's philosophical system—logic, philosophy of nature, and philosophy of spirit—can be regarded as the dialectical development of the spirit from "in-itself" to "for-itself" and finally "in-and-for-itself" which is freedom. Logic is the activity of spirit within itself, philosophy of nature is the externalization of spirit, and philosophy of spirit is the return of spirit from the outside to itself. Hegel's first mature work, Phenomenology of Spirit, is generally regarded as the "introduction" of Hegel's philosophical system and also the science of "spiritual phenomena" which is expounded in a systematical way. In Hegel's view, spirit is the unity of substance and subject or reality and concept, and the realization of such unity is the process of dialectical development. In Phenomenology of Spirit, the spirit has experienced three stages: the subjective spirit (Consciousness, Self-consciousness, Reason), objective spirit (Spirit, Culture, and Morality), and absolute spirit (Religion and Absolute Knowing). The subjective spirit and objective spirit have not yet reached its self-awareness. It is still in the objects, and has not yet returned to itself, so it hasn't reached the unity of the object and self. At the absolute stage, the spirit reaches self-consciousness, that is, the spirit realizes itself as the unity of concept and reality.

In Philosophy of Mind, Hegel describes the relationship among subjective spirit, objective spirit, and the absolute spirit as follows: 
The concept of mind has its reality in the mind. That this reality be knowledge of the absolute Idea and thus in identity with the concept, involves the necessary aspect that the implicitly free intelligence be in its actuality liberated to its concept, in order to be the shape worthy of the concept. The subjective and the objective mind are to be regarded as the way on which this aspect of reality or existence develops itself. (Hegel 2007, 257)

Therefore, subjective spirit (or mind) and objective spirit are the preparations for the absolute spirit. "The absolute mind is identity, both an identity that is eternally within itself and an identity that returns and has returned into itself: the one and universal substance as spiritual, the judgement discerning itself into itself and an awareness, an awareness for which the substance is as such” (Hegel 2007, 257). It can be seen from the above description that spirit or absolute spirit is the unity of reality and concept. The reality of spirit is a series of concepts as its cognition, and when it reaches the identity of concept and reality, it turns into absolute spirit. At the same time, the absolute spirit is the absolute substance, which judges itself and forms knowledge of itself, so the absolute substance is also the subject. Spirit is the unity of substance and subject, concept and reality. However, this unity is not readily available in Hegel's philosophy, but is achieved through the dialectical development of spirit.

The concept of "spirit" is not only the standpoint of Hegel's philosophy, but also the starting point of his aesthetic thought. Spirit as the unity of subject and substance, the unity of concept and reality is not only the guiding thread of Hegel's aesthetic discussion, but also the goal of his aesthetics. As an aesthetic object, art is the first phase of Hegel's absolute spirit. Art is different from subjective spirit and objective spirit because it is in the same field as religion and philosophy. Just as the whole of Hegel's philosophy is the "spirit" as substance and subject, art is also a way for the spirit to achieve its self-awareness and self-realization. At the same time, like religion and philosophy, art is also an absolute understanding. Art, religion, philosophy all take the absolute as object, just in different ways. Art is in the form of perceptual view, religion is in the form of representation, and philosophy takes purely speculative thinking as its way. In Hegel's view, art, religion, and philosophy are all reasonable ways to express spiritual self-knowledge and self-actualization. Hegel's aesthetics is to present the Idea in the perceptual images of art so that spirit can reach its self-awareness, or rather, Hegel's aesthetics is to achieve the unity of the spirit as substance and subject, and as concept and reality.

\section{The Relationship Between Individuality and Universality in Spirit}

In the process of spiritual self-knowledge and self-realization, one important problem is the relationship between universality and individuality. This problem has its roots in the modern distinction between "logos" and "nous." In ancient Greece, "logos" and "nous" are two important aspects for the manifestation of spirit. However, the modern rationality takes "logos" as the priority. In face of the modern controversy on the rational spirit, "nous" is drawing more and more attention. For example, Heidegger criticizes "logos" (rationality) of the spirit. His perspective of ontology can be regarded as a development and emphasis on the "nous" aspect of spirit. Hegel's philosophy is a dialectical development between nous and logos. The principle of the unity of being and thinking is also the unity of "nous" and "logos" of spirit. Deng Xiaomang clarifies the relationship between "nous" and "logos" of Hegel's philosophy in his book The Tension of the Speculative: A New Research on Hegel's Dialectics (Deng 1992). He points out that in his early times, which is in the period of Phenomenology of Spirit, Hegel emphasizes the "nous" spirit. However, when Hegel writes Encyclopedia of the Philosophical Sciences, the phenomenon of spirit is only taken as a moment of the subjective spirit. That is to say, Hegel's philosophical system starts from "logos." In the system, phenomenology retreats behind the scenes, 
and the spirit is also incarnated as logic. Spirit cannot be saved until the development of logic and logos is completed (Deng 2014, 24). In other words, Hegel's philosophy has experienced from "nous" spirit to "logos" spirit. But it is also noted that when spirit returns to itself, "nous" and "logos" are united again.

The two aspects of spirit, namely "nous" and "logos" can be taken as "spirit" (in the narrow sense) and "reason." "Spirit” and "reason" represent universality and individuality respectively. In Phenomenology of Spirit, the transition from reason to spirit has gone through two stages: reason as lawgiver and reason as testing laws. "Reason" here refers to human reason, and "Spirit" refers to the "spirit" in the cultural, social, and historical sense. In the first stage, reason or individual reason takes itself as universal, that is, I = We, but Hegel points out that there is another dimension, that is, We $=\mathrm{I}$. Only "We" can make individual reason possible. After "reason as lawgiver" and "reason as testing laws," individual rationality becomes moral, then it transits to Kant's practical rationality. Kant's practical reason starts from the free will of individual, requiring the consistency of individual-self and universal-self. This principle is embodied in Kant's moral law, "So act that the maxim of your will could always hold at the same time as a principle of a universal legislation" (Kant 2002, 45). However, Kant's law of practical reason is only formal and lacks concrete practical content. Therefore, the unity of individuality and universality is only achieved in a formal way. On the contrary, Hegel turns the rational and individual "I" to the spiritual and universal "We." At the same time, he believes, if there is no "We," there will be no "I" and the "We" is the reality of experience. Kant's transcendental ego is the individual's self-consciousness, while Hegel puts more emphasis on the collective, social, and interrelated "self," namely spirit.

In a narrow sense, Hegel's concept of "spirit” is dominated by universality. Hegel believes that spirit is a universal self-consciousness, and spirit is the unity of self and object. Spirit is more universal than self-consciousness. Hegel said,

A self-consciousness, in being an object, is just as much "I" as "object”. With this, we already have before us the Notion of Spirit. What still lies ahead for consciousness is the experience of what Spirit is-this absolute substance which is the unity of the different independent self-consciousnesses which, in their opposition, enjoy perfect freedom and independence. "I" that is "We" and "We" that is "I". (Hegel 1977, 110)

Therefore, the spirit is a real substance, a universal and indestructible absolute substance. Opposite to spirit are a variety of independent self-consciousnesses which exist for themselves. But spirit can contain the opposite within itself. Therefore, the spirit is the unity of absolute substance and a variety of self-consciousnesses. The universality of spirit is reflected in that spirit is both "I" and "We." If the self-consciousness represents the small "I," the spirit is the big "We." "I" is individuality. There are mutual differences between individuals. "We" represents the universality. Universality integrates individual differences of "I"s into itself and meanwhile keeps their independence and freedom. In a word, the spirit is a universal substance that integrates the individual into itself.

In a broad sense, spirit is the unity of universality and individuality. Although spirit is universal, the universality of the spirit contains the individuality, and the individuality of the spirit is meaningful only as the universal individuality. Spirit is a collective subject, but as a collective subject, spirit is neither a simple individual nor a universal whole. Spirit contains both individuality and universality, which is what Hegel takes as "I that is We" and "We that is I." There is a dialectical relationship between individuality and universality. In Hegel's view, the individual is not a single individual who can be separated from the collective, but an 
individual that is "formed" or "cultivated" in the collective or group. At the same time, the group also needs to be admitted by the individual to exist as a collective. Robert Pippin calls it "Hegel's double-dimension and his historicity" (Pippin 2016, 41). The double-dimension is a characteristic of spirit. Ye Xiushan points out that "alienation-externalization” is also "internalization," "the road of freedom” is also "the road of necessity," and "the way-upward” is also "the way-downward" (Ye 2013, 20). Meanwhile, in Pippin's view, Hegel's spirit is not exactly the same as "group subject." In a community, there can be many "group subject"s, such as university, company, hospital, troops, church, and even at different national levels. They can be both compatible and incompatible, but spirit is the unity of rational forms at the highest level in a period of time.

In addition, the spirit as a kind of life form evolves into a variety of social norms. Spirit takes social norms as the authority, but it is also the measure to see whether the social norms achieve the goals set by spirit. For Hegel, spirit regulates the relationship between people. Spirit is the intermediary between self-consciousnesses. Spirit brings self-consciousness with the authoritative standard of reflection (Pinkard 1994, 7-9). Hegel suggests at the end of the chapter on "spirit" in Phenomenology of Spirit that modern people need some kind of collective self-understanding (The Blackwell Guide to Hegel's Phenomenology of Spirit, 2009, xviii). It can be seen that Hegel emphasizes the universality of spirit which contains individuality. Individuality is dependent on the universality. So there exists a dialectical relationship between universality and individuality, and the spirit is the unity of the two.

\section{The Reconciliation Between Individuality and Universality of Spirit in Hegel's Aesthetics}

How to deal with the relationship between the universality and the individuality in spirit is an aesthetic problem left behind in the context of modern aesthetic debate, which also starts from the rationalism and empiricism. The rationalist aesthetics emphasizes logic and conceptual analysis, attaching great importance to the general concept and ignoring the individual and perceptual phenomena. The empiricist aesthetics gives priority to the individual and perceptual phenomena, but it fails to consider the common concept. Aiming at making a compromise between them, Kant's aesthetics opposes to equating beauty with pleasure in the empiricist aesthetics and also objects to equating beauty with perfectivity in the rationalist aesthetics. Instead, Kant combines pleasure and purposiveness. Kant's aesthetic theory is mainly composed by the "aesthetic judgment" in Critique of Judgement, which analyzes beauty and sublimity and also expounds the ideal of beauty and the status of genius in art. However, there are many contradictions in Kant's aesthetic thoughts. Zhu Guangqian, a late Chinese aesthetician points out in his A History of Western Aesthetics, that Kant often makes a unified thing apart, thinking about the opposites abstractly and making them absolute opposites. The attempt that Kant makes to reconciliate the opposites is unsuccessful. This insight applies to both Kant's philosophy and his aesthetics. In terms of aesthetics, Kant can't reconcile the absolute oppositions between the pure beauty and dependent beauty, between the beautiful and the sublime, between the natural beauty and the artistic beauty, between aesthetic interest and talent (that is, the appreciation and creation), and also between beauty and goodness (Zhu 2011, 441). At the same time, the contradictions of Kant's aesthetic thought are also embodied in the relationship between content and form, subjectivity and objectivity, rationality and sensibility. Zhu Guangqian believes that Kant's problem is due to the fact that he has a dialectical tendency, but with the bundle of transcendental reason, his handling of the contradictions is done in a mosaic way, not the real "unity" (Zhu 2011, 444). So, while Kant's aesthetics makes an effort for the reconciliation between the empiricism and rationalism and makes the problem more clearly, but he still achieves no real reconciliation, especially 
considering the problem of universality and individuality, which embodies in content and form, the subjective and the objective and rationality and sensibility. Hegel's aesthetics is to explore the problem of modern aesthetics further. He takes art as the object of scientific research, gives priority to the relationship between the content and the form of art, and explores the relationship between the universality and the individuality. Besides, based on the relationship between universality and individuality of the spirit, the unity between the sensible and the rational, and the integrity between the substantive and the conceptual are achieved.

First of all, the integration of universality and individuality of the spirit is revealed in the unity of content and form. In Hegel's view, a work of art is the externalization of concept and the content of art is universal and substantive things. But the concept externalizes itself in works of art as the unity of content and form, so it also has individuality. Through artworks which are unity of universality and individuality, the spirit achieves its own understanding and re-understanding. Hegel points out,

And even if works of art are not thought or the Concept, but a development of the Concept out of itself, a shift of the Concept from its own ground to that of sense, still the power of the thinking spirit lies in being able not only to grasp itself in its proper form as thinking, but to know itself again just as much when it has surrendered its proper form to felling and sense, to comprehend itself in its opposite, because it changes into thoughts what has been estranged and so reverts to itself. And in this preoccupation with its opposite the thinking spirit is not false to itself at all as if it were forgetting and abandoning itself thereby, nor is it so powerless as to be unable to grasp what is different from itself; on the contrary, it comprehends both itself and its opposite. For the Concept is the universal which maintains itself in its particularizations, overreaches itself and its opposite, and so it is also the power and activity of cancelling again the estrangement in which it gets involved. Thus the work of art too, in which thought expresses itself, belongs to the sphere of conceptual thinking, and the spirit, by subjecting it to philosophic treatment, is thereby merely satisfying the need of the spirit's inmost nature. (Hegel 1975, 12-13)

It can be seen that art is a way of spiritual self-satisfaction, and art is the "most basic and essential need" of spirit, because in artworks, "the power of the thinking mind" can be shown. In Hegel's view, artworks' manifestation of the spiritual activity is the externalization of the concept itself into sensible things and then from the sensible back to the spirit itself. In the process of externalization and return, spirit achieves its own understanding and re-understanding. Moreover, in art, the sensible as aspect of the reality of art, is not the ready-made perceptual experience of the world, but coming from the externalization of concepts, so the sensible also has spiritual characteristics.

Only beyond the immediacy of feeling and external objects is genuine actuality to be found. For the truly actual is only that which has being in and for itself, the substance of nature and spirit, which indeed gives itself presence and existence, but in this existence remains in and for itself and only so is truly actual. (Hegel 1975, 8)

What Hegel refers to here as "in and for itself" and the "truly actual" is the universal substance in human spirit, such as ethical spirit and moral spirit. They are spiritual realities, higher objects than things in the everyday world. In art, the content of the substantive things is universal, but substance has to appear in the individual form. Therefore, the work of art is the unity of universality and individuality.

When Hegel talks about the artistic beauty or the Ideal of beauty, his definition of the Ideal also starts from the unity of universality and individuality. In art, the unity of content and form is the prerequisite for the Ideal of beauty. The main content of the ideal art, he thinks, is the universally divine substance, but it also needs the individual form. Both the self-sufficient gods in the ancient Greek myths and the Christian God are individually dependent. Human beings, such as saints and martyrs, whose souls are attached to god, are also in the 
individual forms. Other limited and earthly people are shown in an individual way too. However, it should be pointed out that although Hegel emphasizes the unity between content and form, he still puts more weight on content because form depends on content. Most importantly, it is necessary to have a universal and substantive content in order to make the appropriate form to correspond to it and to achieve the harmony between the two. "Now further, in this connection, the Ideal proves effective in the sphere of the mundane and the human in the sense that any more substantial content which preoccupies mankind has power to master the purely particular element in subjective life” (Hegel 1975, 177). It can be seen that Hegel holds that only with the substantive and universal content, the individual expression is able to get rid of the contingency and arbitrariness, so it can show more reality, and can be promoted to the spiritual things. What cannot be ignored is that individuality is also necessary for the realization of spirit. Therefore, in the unity of the content and form of artworks, spirit realizes self-knowledge as the unity of universality and individuality.

In Hegel's aesthetics, apart from the unity of content and form which presents the reconciliation between universality and individuality, the artistic figure, especially the theatrical figure is another manifestation. The dramatic figure is the unity of the world of general situation and individual character. Hegel calls such a figure as the "ideal personality."

But in the Ideal it is precisely particular individuality which should remain inseparable concord with the substantial, and, just as freedom and the independence of subjectivity belong to the Ideal, in the same way the surrounding world of situations and circumstances should not possess any essential objectivity independent of the subjective and individual. (Hegel 1975, 181)

The "ideal personality" is the unity of substantiality and subjectivity, universality and individuality. Only characters with personality which is the unity of the above aspects are independent, self-sufficient, and free.

In Homer's epic, for example, both the gods and the heroes show individual independence and self-sufficiency. Their desire, impulse, and will represent the moral ideal of reality. They take their own character as the law of action and are not bound by external laws. At the same time, "ideal personality" can achieve reconciliation between individual freedom and universal necessity. With independence and self-sufficiency, the heroes of ancient Greece freely bear the fate of necessity while acting freely. The same is true of Greek tragedy. Ancient Greek tragic characters such as Oedipus, Antigone also have the independent personality of self-sufficiency. When there are conflicts between their individuality and the universal substance, the independent and self-sufficient individuals are responsible for the consequences of their action. In form of self-sacrifice on the individual part, the individual and the universal, the subjective and the substantive reconcile with each other. In addition, in Hegel's view, compared with the modern society, the hero's personality is more ideal, because in the heroic age people are not separated from his ethical society as a whole. "In that identity the substantial is immediately individual and therefore the individual is in himself substantial" (Hegel $1975,189)$. The "ideal personality" is the unity of universality and individuality. Figures with such personality are able to act independently and self-sufficiently. They are responsible for the consequences of their own action. Spirit reaches self-awareness and self-realization through these figures with "ideal personality."

In addition, the reconciliation between the universality and the individuality discussed in Hegel's aesthetics is also reflected in the relationship between the subjectivity of artists and the objectivity of manifestation. Artistic works are the result of the artist's spiritual creation. Hegel believes that an artist's creative activities depend on his artistic imagination, genius, and inspiration, which reflect the artist's 
subjectivity and individuality. But Hegel also points out that the artist is just a form. Artists need to indulge themselves in the substantive objective content. Their subjective spirit can play its role only by giving shape to the intrinsic connotation. At the same time, in Hegel's view, the real objectivity of art lies in the unity of the subjective and the objective. He said,

In this connection, keeping to the essential nature of the Ideal, we may affirm as follows what true objectivity is, even here as regards subjective expression: from the genuine subject-matter which inspires the artist, nothing is to be held back in his subjective inner heart; everything must be completely unfolded and indeed in a way in which the universal soul and the substance of the chosen subject-matter appears emphasized just as much as its individual configuration appears completely polished in itself and permeated by that soul and substance in accord with the whole representation. (Hegel 1975, 290)

Here Hegel emphasizes that the artist's spirit of subjectivity needs to obtain objective expression. At the same time, this kind of expression is an individual image with universality and reality. Therefore, through the artist's subjectivity and the objectivity of the performance, art helps to achieve the reconciliation between universality and individuality in spirit.

Hegel tries to reconcile the universality and the individuality of spirit in his aesthetics in order to solve the problem of subjectivity in the modern world. On the one hand, it is done through the relationship between content and form of the artistic Ideal. On the other hand, he makes it through the unified expression between the general world situation and the characters in the "ideal personality." Moreover, it is also embodied in the artist's creative activities which aim to achieve the unity of subjectivity and objectivity. In Hegel's view, artworks are the unity of content and form, in which content is the universal substance, while form is the external image with individuality. At the same time, in characters of "ideal personality," the universal substance and individual subject are in a state of coordination, the ideal characters in its independent and self-sufficient manner both individual and substantive. In addition, the artist has a unique spirit of individuality and subjectivity, such as imagination, genius, and inspiration, but these personalities need to be embodied in the content of reality in order to constitute the true objectivity. Therefore, in Aesthetics, Hegel achieves the goal of the reconciliation between universality and individuality in the above three aspects, thus realizing the self-consciousness of the spirit.

\section{Conclusion}

In order to fill the gap between binaries caused by the modern philosophy and aesthetics, Hegel, taking "spirit" as the starting point, explains the dialectical development between substance and subject, between concept and reality. At the same time, his philosophy is also committed to achieving the self-consciousness and self-realization of the spirit. In this process, how to deal with the relationship between universality and individuality in spirit becomes the key issue. Hegel's philosophy has experienced from the "nous" spirit to the "logos" spirit, and finally achieves the unification of the two. Hegel's "spirit" is both individual and universal. In line with the philosophical goals, Hegel's Aesthetics is also committed to the reconciliation between the universality and the individuality in spirit. In art, reconciliation between the two is mainly manifested in three aspects, namely the unity of content and form, the unity of the general world situation and the character, and finally the unity of subjective artistic creation and objective performance. In this way, Hegel's Aesthetics bridges the distance between individuality and universality, achieving the goal of self-awareness and self-realization in spirit. The reconciliation between the universality and the individuality in spirit is the task of Hegel's Aesthetics. 


\section{Works Cited}

Bosanquet, Bernard. A History of Aesthetics. Trans. Zhang Jin. Beijing: The Chinese People’s Publishing House, 2010.

Deng, Xiaomang. The Tension of the Speculative: A New Research on Hegel's Dialectics. Hunan: Hunan Education Press, 1992.

---. Explanation of Hegel's Phenomenology of Spirit. Vol. 1. Beijing: People's Publishing House, 2014.

Hegel, G. W. F. Aesthetics: Lectures on Fine Art. Vol. 1. Trans. T. M. Knox. Oxford: Clarendon Press, 1975.

---. Phenomenology of Spirit. Vol. 1. Trans. A. V. Miller. Oxford: Oxford University Press, 1977.

---. Hegel's Philosophy of Mind. Trans. W. Wallace \& A. V. Miller. Oxford: Clarendon Press, 2007.

Kant, Immanuel. Critique of Practical Reason. Trans. Werner S. Pluhar. Cambridge: Hackett Publishing Company, Inc., 2002.

Pippin, Robert. “Hegel on Self-deception.” Trans. Zhang Jian. World Philosophy 5 (2016): 41.

Terry, Pinkard. Hegel's Phenomenology: The Sociality of Reason. Cambridge: Cambridge University Press, 1994.

The Blackwell Guide to Hegel's Phenomenology of Spirit. Ed. Kenneth R. Westphal. Hoboken, NJ: A John Wiley \& Sons, Ltd., Publication, 2009.

Ye, Xiushan. “On ‘Freedom’ and 'Necessity’: Thoughts on Hegel’s Philosophy.” Journal of Graduate School of Chinese Academy of Social Sciences 1 (2013): 20.

Zhu, Guangqian. A History of Western Aesthetics. Vol. 2. Beijing: Commercial Press, 2011. 